\title{
OPERATOR INEQUALITIES INVOLVING THE ARITHMETIC, GEOMETRIC, HEINZ AND HERON MEANS
}

\author{
Jianguo Zhao, Junliang Wu, Haisong CAO And Wenshi LiaO
}

Abstract. In this paper we present two improved arithmetic-geometric inequalities with Kantorovich constant (Lemma 3 and Lemma 5), based on which we provide some refinements in the operator case and then finally refer to the operator inequalities involving Heinz and Heron means.

Mathematics subject classification (2010): 15A45,15A60.

Keywords and phrases: Heinz means, operator inequality, positive operator, Kantorovich constant, Heron mean.

\section{REFERENCES}

[1] R. BHATIA, Interpolating the arithmetic-geometric mean inequality and its operator version, Linear Algebra Appl. 413 (2006), 355-363.

[2] T. FuRUtA AND M. YANAGIDA, Generalized means and convexity of inversion for positive operators, Amer. Math. Monthly. 105 (1998), 258-259.

[3] T. FURUTA, Invitation to linear operators: From matrix to bounded linear operators on a Hilbert space, Taylor and Francis, 2002.

[4] T. Furuta, J. MičIĆ Hot, J. PeČARIĆ, Mond-Pečarić Method in operator inequalities, Element, Zagreb, 2005.

[5] S. FURUICHI, On refined young inequalities and reverse inequalities, J. Math. Inequal. 5, 1 (2011), 21-31.

[6] S. Furuichi, Refined Young inequalities with Specht's ratio, J. Egypt. Math. Soc. 20 (2012), 46-49.

[7] O. Hirzallah, F. Kittaneh, M. Krnić, N. LovričEvić And J. Pečarić, Eigenvalue inequalities for differences of means of Hilbert space operators, Linear Algebra Appl. 436 (2012), 1516-1527.

[8] O. Hirzallah And F. Kittaneh, Matrix Young inequaliy for the Hilbert-Schmidt norm, Linear Algebra Appl. 308 (2000), 77-84.

[9] C. J. HE AND L. M. Zou, Some inequalities involving unitarily invariant norms, Math. Inequal. Appl. 12, 4 (2012), 767-774.

[10] F. Kittaneh, M. KRnić, N. Lovričević And J. PEČARić, Improved arithmetic-geometric and Heinz means inequalities for Hilbert space operators, Publ. Math. Debrecen, 80/3-4 (2012), 465478.

[11] F. Kubo And T. Ando, Means of positive operators, Math. Ann. 264 (1980), 205-224.

[12] M. KRnIĆ, N. LOVRIČEVIĆ AND J. PEČARIĆ, Jensen's operator and applications to mean inequalities for operators in Hilbert space, Bull. Malays. Math. Sci. Soc., 35, 1 (2012), 1-14.

[13] J. WU AND J. ZHAO, Operator inequalities and reverse inequalities related to the Kittaneh-Manasrah inequalities, Linear and Multilinear Algebra. in press.

[14] H. L. Zuo, G. H. Shi AND M. FuJiI, Refined Young inequality with Kantorovich constant, J. Math. Inequal. 5 (2011), 551-556. 